\title{
SHARP INEQUALITIES RELATED TO ONE-PARAMETER MEAN AND GINI MEAN
}

\section{HONGYA GAO AND WENJUAN NIU}

Abstract. In the present paper, we answer the question: For $\alpha+\beta \in(0,1)$, what are the greatest values $p, s_{1}$ and the least values $q, s_{2}$ such that the inequalities

$$
J_{p}(a, b) \leqslant A^{\alpha}(a, b) G^{\beta}(a, b) H^{1-\alpha-\beta}(a, b) \leqslant J_{q}(a, b)
$$

and

$$
G_{s_{1}, 1}(a, b) \leqslant A^{\alpha}(a, b) G^{\beta}(a, b) H^{1-\alpha-\beta}(a, b) \leqslant G_{s_{2}, 1}(a, b)
$$

hold for all $a, b>0$ with $a \neq b$ ? where $J_{p}(a, b), A(a, b), G(a, b), H(a, b)$ and $G_{s, 1}(a, b)$ are the one-parameter mean, arithmetic mean, geometric mean, harmonic mean and Gini mean for two positive numbers $a$ and $b$, respectively.

Mathematics subject classification (2010): 26D99.

Keywords and phrases: One-parameter mean, Gini mean, arithmetic mean, geometric mean, harmonic mean.

\section{REFERENCES}

[1] W. S. Cheung AND F. QI, Logarithmic convexity of the one-parameter mean values, Taiwanese J. Math. 11, 1 (2007), 231-237.

[2] F. Qi, P. Cerone, S. S. Dragomir AND H. M. SRivastava, Alternative proofs for monotonic and logarithmically convex properties of one-parameter mean values, Appl. Math. Comput. 208, 1 (2009), $129-133$.

[3] N. G. Zheng, Z. H. ZhANG AND X. M. ZHANG, Schur-convexity of two types of one-parameter mean values in $n$ variables, J. Inequal. Appl. 2007, Art. ID 78175, 10 pages.

[4] P. A. HÄstö, A monotonicity property of ratios of symmetric homogeneous means, J. Ineq. Pure Appl. 3, 5 (2002), article 71 .

[5] E. B. Leach And M. C. Scholander, Extended mean values, Amer. Math. Monthly 85 (1978), 84-90.

[6] E. B. Leach And M. C. Scholander, Extended mean values, II, J. Math. Anal. Appl. 92 (1983), 207-223.

[7] L. E. Persson And S. SJÖstrand, On general Gini means and scales of means, Results Math. 18, 3-4 (1990), 320-332.

[8] K. B. Stolarsky, The power and extended mean values, Amer. Math. Monthly 87, 7 (1980), 545548.

[9] P. S. Bullen, D. S. Mitrinovic And P. M. Vasic, Means and their inequalities, D. Reidel Pubishing Co., Dordrecht, 1988.

[10] H. Alzer AND W. Janous, Solution of problem 8, Crux Math. 13 (1987), 173-178.

[11] Q. J. MAO, Power mean, logarithmic mean and Heronian dual mean of two positive number, J. Suzhou Coll. Edu. 16, 1-2 (1999), 82-85.

[12] M. K. WANG, Y. F. QIU AND Y. M. ChU, An optimal double inequality among the one-parameter, arithmetic and harmonic means, Revue D'Analyse Numérique et de Théorie de L'approximation 39, 2 (2010), 169-175. 